\title{
The Loss of Biodiversity as a Challenge for Sustainable Development: How Do Pupils in Chile and Germany Perceive Resource Dilemmas?
}

\author{
Susanne Menzel • Susanne Bögeholz
}

Published online: 21 June 2008

(C) The Author(s) 2008

\begin{abstract}
The topic of biodiversity is of high value for education for sustainable development as it reflects the interaction of ecological, economic and social issues particularly well. Especially in so-called biodiversity hotspots, among them Chile, natural resources are often depleted for economic interest which, in many cases, is required income. Therefore, economic and social aspects must be considered in order to fully understand biodiversity loss. Being such an important issue, it is surprising that little is known thus far about learning prerequisites concerning biodiversity. This paper presents a qualitative interview study that investigated 16 to 18 -year-old Chilean and German learners' perception of biodiversity and its loss $(n=24)$. Firstly, the pupils' cognitive frameworks were analysed. Secondly, subjective theories about biodiversity loss due to resource dilemmas were explored. Three subjective theories that emerged from the data reflected the notion that most pupils focused on either ecological or economic aspects of biodiversity loss. Pupils who concentrated on ecological aspects often referred to incorrect ecological facts. Moreover, these pupils showed difficulties in developing empathy and solidarity with impoverished people, who depend economically on plants in a resource dilemma. A smaller group of pupils succeeded in integrating the ecological, economic, and social aspects. Regarding the two samples, Chilean pupils seemed to have greater difficulties in recognising the social aspects of biodiversity loss, while German pupils were largely unaware of biodiversity loss on a local level. Implications for biodiversity education and future research will be outlined and discussed.
\end{abstract}

S. Menzel $\cdot$ S. Bögeholz

Centre for Empirical Research in Instruction and Learning (ZeUS), Didactics of Biology, Georg-August-University Göttingen, Waldweg 26, 37073 Göttingen, Germany

S. Bögeholz

e-mail: sboegeh@gwdg.de

Present address:

S. Menzel $(\bowtie)$

Department of Biology and Chemistry, Didactics of Biology,

Universität Osnabrück, Barbarastr. 11, 49069 Osnabrück, Germany

e-mail: menzel@biologie.uni-osnabrueck.de 
Keywords Education for sustainability - Biodiversity education - Subjective theory $\cdot$ Chile $\cdot$ Germany $\cdot$ Resource dilemmas

\section{Introduction}

If we understand education for sustainable development first and foremost as a learning process (Huckle and Sterling 1996; Scott and Gough 2003; Sterling 2001), the learner's perspectives are key factors in making educational measures meaningful or meaningless for an individual. This is especially true for issues of education for sustainability, being as they are: complex, interdisciplinary, uncertain and encompassing ethical issues like risk and necessity (Barkmann and Bögeholz 2003; Scott and Gough 2003). For education for sustainable development, the topic of biodiversity is of high educational value as the main challenges for sustainable development are reflected in the issue (Dreyfus et al. 1999; Mallow 1994; Van Weelie 2002). Moreover, biodiversity conservation is - and has always been - a central issue in the context of sustainable development (UNCED 1992; WCED 1987; Wilson 2001). Nevertheless, from an educational perspective, biodiversity is a two-edged sword. This is especially due to (at least) three aspects that might pose a particular challenge for learners. Firstly, it might be confusing that the terms 'biodiversity' and 'biological diversity' are identical in meaning and they are commonly understood to be a synonym for 'the variety of species'. Accordingly, in science education and science education research, the biodiversity concept is still often equated with and, consequently, reduced to the variety of species (Balmford et al. 2002; Bebbington 2005; Kassas 2002; Lindemann-Matthies 2006). Unfortunately, such an understanding has shortfalls, because the term 'biodiversity' also refers to the diversity of ecosystems and genetic diversity (see, e.g., Townsend et al. 2003).

A second challenge might be the fact that reasons for and consequences of biodiversity loss surround complex ethical, economic and social issues (e.g. WCED 1987; Wilson 2001). In the understanding of learners, however, the term 'biodiversity' might suggest an ecological focus, also when they think about reasons for biodiversity loss. From a sustainability perspective, an adequate understanding of biodiversity and biodiversity loss cannot be achieved under such a restricted perspective.

A third challenge for learners is the global dimension of the problem. The loss of biodiversity is especially urgent in so-called 'biodiversity hotspots': regions in which a large amount of the original flora and fauna has already been depleted (Mittermeier et al. 2004). Chile can be seen as an example of one such hotspot region. In many cases biodiversity hotspots are located in poor countries, a situation that imposes additional pressure upon biodiversity. Nevertheless, reasons for biodiversity loss in hotspots are not exclusively due to the local situation, but rather due to complex global cause-and-effect chains. Thus, industrial countries, where the problem of biodiversity loss might be less urgent on a local scale, bare the same responsibility for biodiversity loss. To the learner, these interrelations might be neither obvious, nor easy to understand.

The three above-mentioned challenges for an understanding of biodiversity loss are particularly reflected in so-called resource dilemmas (e.g. Cincotta et al. 2000; Ernst 1997; Hardin 1968; WCED 1987). Resource dilemmas are situations, in which impoverished people depend economically on the exploitation of natural resources. In such dilemmas, a common, open-access resource is used, and in many cases overused, by multiple parties. Resource dilemmas are difficult to understand for individuals, as, in many cases, consequences of an exploitation of natural resources occur spacio-temporal shifted. In order to understand resource dilemmas, one has to i) overcome disciplinary boundaries in thinking and ii) integrate complex 
facts and ethical values (Barkmann and Bögeholz 2003). However, past research has shown how difficult this may be for both, pupils (Grace and Ratcliffe 2002; Menzel and Bögeholz 2006) and teachers (Gayford 2000; Summers et al. 2005). This paper aims at exploring and describing pupils' perception of biodiversity and biodiversity loss with resource dilemmas as an example. The aim is to identify perception patterns in pupils that might either oppose or foster an understanding of biodiversity and biodiversity loss.

\section{Theoretical Background}

According to constructivism, humans are active and subjective constructors of their own knowledge (e.g. Caravita and Halldén 1994; Carey 1985; von Glasersfeld 2005; Piaget 1974). This means, from early childhood on, each person develops individual cognitive patterns through which reality is constructed (Carey 1985). During such construction processes, learners actively process information by either accommodating (i.e. adapting) their own cognitive structures or assimilating information, in order to make it fit into the current worldview (Piaget 1974). With respect to the above, science education research has shown that it is often difficult to alter a pupil's existing conceptual structure and, thus, to achieve accommodation (Posner et al. 1982; Vosniadou 1992). This is especially true if previously held ideas are subjective theories, which are particularly resistant to change (Groeben et al. 1988; Vosniadou 1992). Due to this tendency to be stable, prior knowledge and ideas can be an obstacle for the learning process, especially when they are opposed to the content to be learned.

Such obstacles may play an important role when pupils are confronted with the complex issue of biodiversity. For teaching processes that aim at a better understanding of the biodiversity concept, it can, therefore, be helpful to be aware of pupils' prior cognitive frameworks (Duit and Treagust 2003). If teachers show such awareness, learning interventions can actively address priory existing cognitive frameworks to enhance the learning process.

According to Groeben et al. (1988) cognitive frameworks can be represented at different levels of complexity. The more complex cognitive structures are, the more are they robust towards change. Less complex cognitive frameworks than subjective theories are, for instance, associations and concepts (Fig. 1).

Associations are the least complex level of a cognitive framework; they are defined as spontaneously manifested links between terms or broad ideas (Strube 1984). Associations can shed light on more complex cognitive structures such as concepts, or subjective theories. Concepts are terms or ideas per se, which a person acquires (Groeben et al. 1988). However, these concepts do not usually show complex relations amongst each other, nor do they span contexts. On the other hand, subjective theories do. Like scientific theories, they serve as an explanatory means and have, therefore, constitutional function for reality. Subjective theories are

Fig. 1 The structure of cognitive frameworks (after Groeben et al. 1988). Subjective theories are complex aggregates of concepts and have similar functions than scientific theories. Concepts can be linked through (implicit) argumentation structures, which may become apparent during an interview, e.g. through spontaneously manifested associations
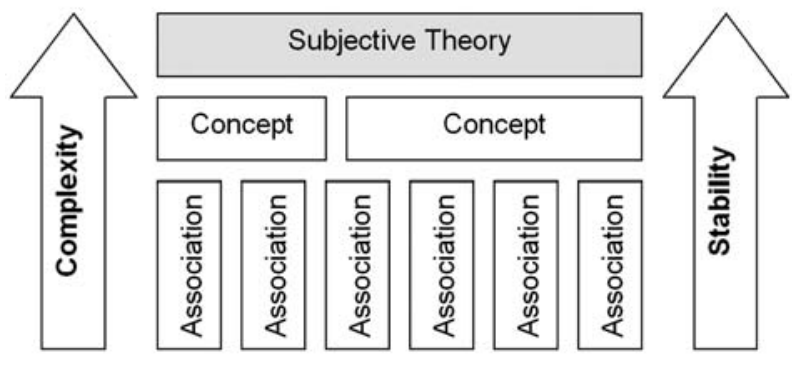
'complex aggregates of argumentation structures and less complex cognitions, such as concepts' (Groeben et al. 1988, p. 19). They are often implicit and, thus, unconscious to the learner. Being the most stable of cognitive structures, prevalent subjective theories are of special interest for teaching and learning, particularly when they oppose the contents to be learned.

Through a person's argumentation strategy, underlying cognitive frameworks can become apparent (Groeben et al. 1988). Thus, a thorough analysis of arguments can be useful for investigating the pupil's cognitive frameworks.

\section{Research Questions}

The present study explored German and Chilean pupils' cognitive frameworks related to biodiversity, its distribution, endangerment, and value. We were especially interested in the question whether pupils would be able to recognize the structure of resource dilemmas, as they reflect the challenges for sustainable development particularly well. Additionally, we focused on whether the pupils' cognitive frameworks reflect a well-balanced acknowledgement of ecological, economic, and social aspects. Hence, our research questions were as follows:

1. What cognitive frameworks (associations, concepts, or subjective theories) can be identified among German and Chilean pupils, concerning the terminology, distribution, loss, and value of biodiversity?

2. What subjective theories can be identified in German and Chilean pupils with regard to biodiversity and its loss, especially with regard to resource dilemmas?

3. Which differences can be identified between the pupils of the German and the Chilean sample?

\section{Methods}

Our sample consisted of 24 pupils, 12 of them Chilean, 12 of them German (Table 1). The sample from Chile was chosen due to the fact that central Chile is an example of a region that contains both, a biodiversity hotspot, and a resource dilemma. Here, the pressure on biodiversity is, among other things, especially high due to Chile's emerging market. Economic development is currently of high priority in Chile, while ecological standards are still low (Scholz 1999). In contrast, Germany is an industrial country with a medium level of biodiversity. Although biodiversity loss also occurs in Germany, pupils might perceive resource dilemmas from a different perspective. Situations, in which people depend on the exploitation of natural resources for means of subsistence, might appear more abstract to pupils in an industrial country. Chilean pupils, in contrast, might more accurately perceive the ethical complexity of resource dilemmas due to their presence within the pupils' direct environment.

Given that the topic of biodiversity is complex and also covers difficult ethical issues, we selected senior pupils between the ages of 16 and 18. To avoid bias, we interviewed pupils from different regions and school types in Germany and different school types in Chile respectively. Following this principle, we included German pupils from rural and urban areas. Some pupils attended a regular secondary school ('Gymnasium'), while others a mixed-level school ('Gesamtschule') in a district, which was characterised by social difficulties. Within the Chilean sample, pupils either attended an exclusive (and expensive) private school, a school free of charge in a suburb with a weak socio-economic background, or a private school with medium tuition 
Table 1 Chosen German and Chilean pupils being interviewed about biodiversity loss

\begin{tabular}{|c|c|c|c|}
\hline Name (modified) & Sex & School type & Age \\
\hline \multicolumn{4}{|c|}{ German sample used in the interviews $(n=12)$} \\
\hline Sebastian & M & \multirow[t]{4}{*}{ Grammar School ("Gymnasium") small town } & 17 \\
\hline Mathias & M & & 18 \\
\hline Katja & $\mathrm{F}$ & & 17 \\
\hline Johanna & $\mathrm{F}$ & & 17 \\
\hline Natascha & $\mathrm{F}$ & \multirow[t]{4}{*}{ Comprehensive School ("Gesamtschule") large city } & 18 \\
\hline Julia & $\mathrm{F}$ & & 17 \\
\hline Anna & $\mathrm{F}$ & & 17 \\
\hline Ayshe & $\mathrm{F}$ & & 17 \\
\hline Simone & $\mathrm{F}$ & \multirow[t]{4}{*}{ Grammar School ("Gymnasium") in the country } & 18 \\
\hline Lilli & $\mathrm{F}$ & & 18 \\
\hline Olaf & M & & 17 \\
\hline Andreas & M & & 17 \\
\hline \multicolumn{4}{|c|}{ Chilean sample used in the interviews $(n=12)$} \\
\hline Ignacio & M & \multirow[t]{4}{*}{ State school (publicly maintained) } & 16 \\
\hline Elena & $\mathrm{F}$ & & 16 \\
\hline Pablo & M & & 17 \\
\hline Paula & $\mathrm{F}$ & & 17 \\
\hline Maria & $\mathrm{F}$ & \multirow[t]{4}{*}{ Semi-public school } & 16 \\
\hline Albáro & M & & 16 \\
\hline Gustavo & M & & 16 \\
\hline Valeria & $\mathrm{F}$ & & 16 \\
\hline Igor & M & \multirow[t]{4}{*}{ Private school } & 16 \\
\hline Rosa & $\mathrm{F}$ & & 17 \\
\hline Carlos & M & & 17 \\
\hline Alma & $\mathrm{F}$ & & 17 \\
\hline
\end{tabular}

fees. By applying the above-mentioned criteria, our sample was relatively diverse. However, due to the small sample size, the samples were neither representative of Chilean, nor German pupils.

The duration of the one-to-one interviews ranged between 35 and 72 minutes. The interviews were conducted in either German or Spanish language, according to the pupil's mother tongue. For the purpose of this paper, citations have been translated into English by the authors from the German or Spanish originals. Data collection took place in each respective school, yet divorced from science classes.

The interviews were structured by a written protocol. The interview protocol consisted of 15 semi-structured questions, mostly with one to three corresponding follow-up questions. Overall, the protocol consisted of three steps (see Table 2).

As a part of step one, general questions were posed about the terms 'biodiversity' and its synonym 'biological diversity', distribution of biodiversity in the world, values, and threats to it. As a first problem-solving task within the interview, several herbal products were presented, in order to find out whether pupils spontaneously linked consumer goods to biodiversity. A second intervention within the first interview step was solely posed orally. As resource dilemmas embody the challenges of sustainable development, in the current study, two examples of resource dilemmas were applied. We decided to choose such resource dilemmas as examples that bear relation to Chilean and German pupils' life.

Medical plants are consumer products that are relevant to young people of i) both sexes, ii) in both countries Chile and Germany and iii) in poor as well as in wealthy socioeconomic 
Table 2 Three-step structure of the interview protocol used in the study

\begin{tabular}{|c|c|c|}
\hline Step & Content & Examples of Interview Questions \\
\hline 1 & $\begin{array}{l}\text { a) General questions about threats for } \\
\text { biodiversity } \\
\text { b) Example: The Devil's Claw } \\
\text { (with detailed interventions, e.g. comments } \\
\text { on the plant collectors' economic situation) }\end{array}$ & $\begin{array}{l}\text { What do you associate with the term } \\
\text { "biodiversity"? What does it mean for a place } \\
\text { to contain high biodiversity? } \\
\text { Who do you think should be made } \\
\text { responsible for the loss of the plant } \\
\text { [Devil's Claw]? } \\
\text { Why do you think would people still collect } \\
\text { and sell plants when the plant is threatened? }\end{array}$ \\
\hline 2 & $\begin{array}{l}\text { Transfer example: Boldo } \\
\text { (without interventions) }\end{array}$ & $\begin{array}{l}\text { Let's talk about Boldo leaves. They are } \\
\text { collected from the wild. What are some of } \\
\text { the problems that you think concern the } \\
\text { extraction, use, and trade of this plant? }\end{array}$ \\
\hline 3 & $\begin{array}{l}\text { Questions about } \\
\text { examples of biodiversity loss and possible } \\
\text { solutions for resource dilemmas }\end{array}$ & $\begin{array}{c}\text { Do you know of any examples where the } \\
\text { trade of particular species (plants or } \\
\text { animals) has reduced their natural livestock? } \\
\text { Do you know any basic approaches for } \\
\text { solving this problem? }\end{array}$ \\
\hline
\end{tabular}

situations. Moreover, we wanted to include at least one dilemma that is neither rooted in Germany, nor in Chile. The dilemma surrounding the South African medical plant Devil's Claw appeared suitable under the above-mentioned perspective. Within a second example, however, we wanted to focus on a local perspective of the Chilean pupils. We, therefore, chose an example from Latin America, which showed very similar characteristics to the dilemma of the Devil's Claw. Hence, within this first interview step, the first resource dilemma was presented by means of the following information:

'An increasing demand for Devil's Claw pharmaceuticals, which serve as a remedy against rheumatism and arthritis, has recently led to a serious decline of the plant in its natural habitat, the Kalahari desert. In order to satisfy the industrial demand mostly emanating from Europe and North America, collections of the plant from the wild are frequent. A ban on collections would stop plant collectors, who are often living in poverty, earning an income.'

Follow-up questions actively aimed at highlighting the economic and social aspects of this first example. For instance, pupils were asked to consider the plant collector's life situation and explain their thoughts.

The example of the Latin American medical plant Boldo (Peumus boldus), in which similar features of the above dilemma can be found, formed the second step of the interview. Due to excessive trading of the plant in Latin American markets, its natural appearance is declining (Vogel et al. 1998). In contrast to the first dilemma example, in this instance, the dilemma was not explained to the pupil in detail, it was only mentioned in one introductory sentence, as presented in Table 2, step 2. This approach was born out of the hypothesis that the way a pupil transferred his or her knowledge to the new situation could shed light on the stability of the pupil's cognitive structure. 
In the third step of the interview, pupils were asked to name further resource dilemmas and to develop possible solutions. Given this approach, the third step was the most abstract step within the interview, one that demanded the greatest amount of independent thinking from the pupil.

All interviews were fully transcribed. The authors then transformed the texts into 'edited declarations' ('redigierte Aussagen' Gropengießer 2001) where the objective was to prepare grammatically correct language. The actual data analysis consisted of two analytical steps. The first analytical step was a deductive analysis of the entire textual material (Miles and Huberman 1994) with a pre-set focus on i) the terms 'biodiversity' and 'biological diversity', ii) the value of biodiversity, iii) distribution of biodiversity in the world, and iv) loss of biodiversity. Having been pre-set, these four categories were reflected by the questions of the interview protocol. However, sub codes for each of the pre-set categories were constructed according to the pupils' answers. Within this first analytical step, we additionally coded responses whenever pupils referred to i) ecological, economic, and social facets or ii) other elements of resource dilemmas (e.g. the role of plant collectors).

Within the second analytical step, subjective theories were explored. A main criterion to identify subjective theories was the stability of the displayed cognitive framework. For example, a spontaneous thought that was uttered after a particular question and which the pupil did not explain further, was considered an association (for example: 'Tropical rainforests are places of high biodiversity'). In contrast, we considered such ideas that were repeatedly displayed, but which did not lead to an explanation of a circumstance, as concepts (for example, when a pupil repeatedly expressed the idea that biodiversity is threatened due to a lack of space in the world). Subjective theories span numerous contexts and serve as an explanatory basis for phenomena across contexts (Groeben et al. 1988). The authors, therefore, considered such cognitive frameworks as subjective theories that emerged repetitively during the interview, across the examples applied (for example, when a pupil repeatedly mentioned ecological reasons to explain biodiversity loss in both dilemma examples and also when suggesting solutions).

Interrater-reliability was pursued by engaging in check coding, as described by Miles and Huberman (1994), in which coding is conducted by at least two independent researchers for all steps of data analysis. Disagreements were discussed and respective text passages recoded in consensus. The final interrater-reliability was calculated to be $90 \%$ across all categories and was considered to be a satisfactory value.

\section{Results and Discussion}

In this first section, results of the pupils' ideas about the terminology, distribution, loss and value of biodiversity are presented and discussed. In a second subsequent 'results and discussion' section, three subjective theories about ecological, economic and social aspects of biodiversity loss and resource dilemmas will be presented, likewise followed by a discussion.

\section{Results and Discussion I}

\section{Terminology Pertaining to Biodiversity}

The German term for biodiversity (Biodiversität) was unknown to all the German pupils interviewed. In all these cases, the term biodiversity was explained to the interviewee before continuing with the interview. All Chilean pupils, however, correctly interpreted the Spanish term for biodiversity (biodiversidad) as identical in meaning to 'biological diversity' (diversidad biológica). In contrast to the term 'biodiversity', its synonym, 
'biological diversity' ('biologische Vielfalt' and 'diversidad biológica' respectively) was known across both samples. A possible explanation for the lower level of familiarity with the term for 'biodiversity' in the German sample could be the fact that the German word 'Diversität' is rather understood as a technical term, while the Spanish term 'diversidad' is much more embedded in everyday language. Both, Chilean and German pupils mostly attributed the terms for 'biodiversity' to the variety of plants and animals. In addition, although less frequently, ecosystems were associated with biological diversity in both subsamples. A statement of Katja provided an example of such an association: 'I would say that [...] a region [rich in biodiversity] has to be relatively multifaceted. There have to be forests for certain animals. There have to be open spaces as well, for bigger animals or other animals [...]' (95-98). ${ }^{1}$ In contrast to the biodiversity of species and ecosystems, the consideration of genetic diversity appeared only indirectly in the case of two German pupils and one Chilean pupil. For example, consider the following statement generated by Katja: 'If they [the animals] were all the same, [...] totally alike concerning the genes [...] they would probably die out easier, I guess. It's because then only one thing has to happen the animal can't get along with [...]. This would, then, affect the entire species' (129-134). However, for most pupils, the concept of genetic diversity seemed to be rather challenging. Furthermore, in both subsamples, a prominent association with the terms 'biological diversity' and 'biodiversity' was diversity within the subject biology, and thus, an interpretation of biodiversity as different biological disciplines.

\section{Distribution of Biodiversity}

Within the German sample, pupils directly associated tropical forests or wilderness areas in Africa and Latin America as being indicative of regions high in biodiversity. We therefore assume that a broad understanding of the distribution of biodiversity seems to exist (even though the term itself was unknown to German pupils). However, it is interesting to note why these areas were viewed as being extraordinarily rich in biodiversity. For example, a popular concept concerning the lack of space in industrial countries includes assumptions that cramped cities with practically no space for plants and animals are regions of extremely low biodiversity. Although more popular among German pupils, the concept was also identified within the Chilean sample. For instance, the Chilean pupil Albáro stated: '[...] I think that poor countries have higher biodiversity because they don't have industry, they don't have anything, it's [still] all here' (729-730, 734). The concept probably derives from everyday-life experiences obtained from living in, or visiting big towns and cities. One reason that it was more popular among German pupils was probably due to a general negative view of urbanisation. In fact, the destruction of natural habitats is a problem for biodiversity preservation in general (Pullin 2002). Nevertheless, pupils seemed to have a very concrete and practical view on the problem, and in doing so, overestimated the negative role of cities. Moreover, the concept rather reflected the situation in modern industrial countries. In fact, however, the pressure on natural environments that surround cities is first and foremost a problem of poor countries (Marshall 1998).

A second popular explanation used to interpret lower biodiversity in certain regions was the concept of climatic characteristics. Here, deserts and Polar Regions were frequently seen as regions of low biodiversity. The concept, upon which these associations were built, seemed to be one that was based on the contention that extreme climatic conditions oppose high biodiversity. Accordingly, one German pupil, Johanna, explained the relatively low

\footnotetext{
${ }^{1}$ The numbers in brackets indicate the line numbers in the original transcript.
} 
biodiversity in Germany as well as in 'warmer' countries by means of the following reasoning: 'In Germany, it could be that the climate is bad here, there is too little sun [and it is] always too wet, so the plants die. [...] And in warmer countries, plants don't have the time to grow' (366-371). In what is probably linked to the same concept, Europe was mentioned as a region of high biodiversity in some cases. For instance, the German adolescent Simone stated: '[Areas of high biodiversity] are more likely to be found here in Europe because the weather is neither extremely hot nor extremely cold, it's [a much larger] spectrum, [suitable] for many living organisms' (139-141). The concept of climatic characteristics might undermine the learning process, as climatic circumstances are not threats to biodiversity per se. For instance, pupils might learn about the fact that biodiversity hotspots are often located in regions where extreme climatic and ecological conditions prevail (e.g. tropical forests with poor soil conditions, deserts containing extraordinary adaptation strategies of plants and animals, or coral reefs that owe their extreme richness in biodiversity to adaptation strategies to the absence of nutrients in the water). Thus, the concept of extreme climatic conditions might oppose an understanding of these important ecological facts.

\section{Loss of Biodiversity}

Besides the concepts of extreme climatic conditions and the lack of space, few arguments were spontaneously given to explain the loss of biodiversity. Before the first dilemma example had been mentioned (see Table 2), only one pupil in the entire sample, the German pupil Lilli, took social reasons for biodiversity loss spontaneously into account. Thereto, Lilli mentioned the following statement: 'I'm thinking of the tropical rainforest [...]. It could be difficult to stem desertification there [...] as pastures are expanding more and more. [Sometimes] nomads are driven away to the south to let their cattle graze there. But it is difficult to do something about this' (284-289). In this regard, and especially with respect to the Chilean sample, the researchers had expected a certain intuitive consideration of social problems as aggravators of biodiversity loss. However, our findings suggest that we cannot assume an easier understanding of socio-economic drivers for biodiversity loss due to the fact that adolescents live in close proximity to a biodiversity hotspot. This finding contradicts our earlier expectations.

Regarding threatened species, Chilean pupils associated numerous local examples, such as the Huemul (an endemic Chilean deer species), the Camote (a Chilean wolf species), or Araucariae (Chilean endemic tree species) rather than considering a global perspective. Within the German sample, only one pupil, Sebastian, mentioned a local example of a threatened species (i.e. Edelweiss, an endemic alpine plant). Generally, international examples, such as whales or elephants, prevailed. For the German sample, the results indicate a lack of awareness for biodiversity loss on the local level, while the same can be noted for Chilean pupils on the global level. This result could at least partly be due to the fact that less species are threatened in Germany than in Chile. Nevertheless, for Germany, the Red List of Endangered Species (IUCN 2007) actually lists 585 animals and 22 plants under threat. Apparently, awareness for this problem was low among the German pupils in our sample.

\section{The Value of Biodiversity}

Within both samples, the value of biodiversity was frequently associated with its value as a food and medicine source. Although these ideas can probably be ascribed to the products presented within step one of the interview, the numerous references to commercial products show that human benefit from biodiversity seemed to be a plausible idea for pupils in both samples. 
Additionally, an economic value of biological diversity, defined as the possibility to establish a market with biological goods, was identified as a concept in both samples, although it was slightly more prominent among Chilean pupils. For example Carlos, a Chilean pupil, expressed such a concept, in which he considered the utilisation of local plant and animal species to be not only of cultural interest but also as a tourist attraction. Besides the already-mentioned, a concept of the aesthetic value of biodiversity was identified among several German pupils (e.g. the beauty of flowers and trees), but rarely occurred within the Chilean sample. In contrast, a very interesting concept that defined biodiversity as a requirement assisting the survival of ecological changes was identified within both samples. The Chilean pupil Albáro provided a datum, which supports this: 'Well, [biological diversity is important] for everybody [...]. It's like history. If one considers the principle of animals, how they live and the changes that they had [to go through] and how they succeeded to pass all these things' (212-216). The aforementioned statement of the German pupil Katja, which described genetic variety as an element of biodiversity, suggested a similar direction in terms of the ability of a species to survive changes due to their genetic flexibility. Thus, Albáro and Katja obviously interpreted high genetic diversity as an insurance for survival, in case of changes in the environment. By doing so, the two pupils rose above a purely human-centred perspective. Thus, they considered a biocentric value of biodiversity.

\section{Results and Discussion II: Subjective Theories About the Loss of Biodiversity}

Sustainable development requires an understanding of social, economic and ecological considerations. The loss of biodiversity and especially the threat of biodiversity due to resource dilemmas can only be understood if pupils connect these three dimensions. During data analysis, it emerged that influential subjective theories, which contained either a strong ecologic, economic, or social stance, influenced the pupils' judgements on the biodiversity problem. During our analysis, three subjective theories emerged across the samples, namely, loss of biodiversity due to ecological reasons, loss of biodiversity due to social reasons and loss of biodiversity due to economic reasons.

\section{Subjective Theory 1: Loss of Biodiversity Due to Ecological Reasons}

The subjective theory 'loss of biodiversity due to ecological reasons' was characterized by a strong focus on ecological aspects of biodiversity and its loss. For example, such a subjective theory was exemplified by the profile of the German pupil Natascha. Throughout the entire interview, ecological drivers (or what Natascha considered to be drivers for biodiversity loss) came to the fore strongly. Such thinking was shown in her explanation of the loss of Devil's Claw, where she emphasized ecological arguments, such as soil conditions or the plant's lack of ability to recover: 'There are some plants [that] don't grow again, once they have been cleared or something [like that]. (647-648) Maybe after a while, [...] nothing grows again. That depends on the soil or the weather' (723-724). This example shows how difficult it is for a learner to go beyond the limits of a prevalent subjective theory. The loss of biodiversity was continuously explained by soil conditions, climate, and a plant's inability to recover after harvesting, often under the guise of erroneous biological knowledge.

During the Boldo transfer example, Natascha's arguments were again strongly influenced by an ecologically orientated subjective theory: '[...] I don't believe that the soil is always producing something, nutrients for example. It's also possible that nutrients get destroyed at a certain point and don't recover. When continuing like that, there'll be the same problem as with the Devil's Claw' (947-950). 
When Natascha suggested possible solutions for resource dilemmas, she briefly considered the protection of wild growing plants. Albeit so, her strong emphasis on ecological factors finally prevailed, which was exemplified by the following quote: 'WWhat we can do] depends on the humans. To pay attention to nature, maybe to grow something. However, it depends on the climate after all' (1203-1204). Her tendency to overlook socioeconomic implications had serious consequences for accurately judging the participants' role in the resource dilemmas. For example, Natascha judged the behaviour of the plant collectors in the case of Boldo as follows:'[I would call the behaviour of the individual participants in the case of Boldo] selfish. Maybe [they] should sometimes think of other people as well. [...] if people go on like that, we soon won 't have nature any more, nothing' (955-957). Analyzing her arguments, we interpreted Natascha's non-existent socioeconomic perspective as a hindrance for considering the perspective of people involved in a resource dilemma. We suggest that the result was a lack of empathy, when it could be argued that she did not have an understanding for those involved at the 'grass roots' level. All in all, the complexity of the resource dilemma concerning the 'biodiversity' topic was not adequately acknowledged in Natascha's responses.

The so-called 'code browser matrix', as produced by the deployed computer programme (MAXqda, Software for qualitative data analysis), proved to be a useful tool to visualize the strong emphasis of ecological arguments, which can also be observed in other pupils besides Natascha (Fig. 2).

When comparing the argumentation structures of those pupils, who generally concentrated on ecological arguments, additional specific characteristics stand out. Firstly, note that the pupils Albáro, Alma, Gustavo, Pablo and Paula (all Chilean) apparently did not consider the Boldo transfer example as a problem. If so, arguments only occurred as concerns about a possible market value of the plant (included under 'economic' arguments). Secondly, a group of three German pupils (Johanna, Anna, Matthias), who displayed the subjective theory 'loss of biodiversity due to ecological reasons', surprisingly mentioned some 'social thoughts' when talking about solutions to biodiversity loss and resource dilemmas. However, social considerations were still overlaid by ecological arguments. Thirdly, a comparison that went beyond the code-matrix revealed that, numerous pupils who showed the subjective theory 'loss of biodiversity due to ecological reasons' referred to ecological arguments that were technically incorrect. Hence, it seems as if pupils started to come up with ecological arguments whenever 'correct' ecological knowledge had shortfalls in explaining the resource dilemmas. It can, therefore, tentatively be concluded, that an ecological focus did not automatically

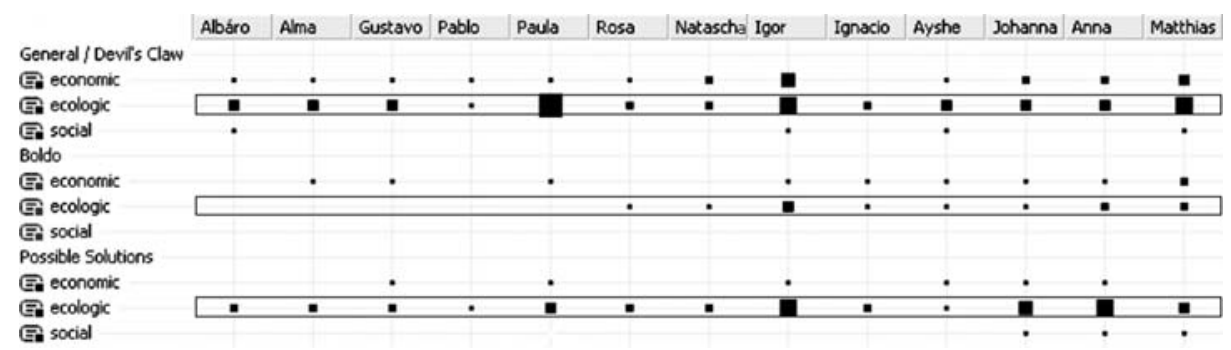

Fig. 2 Subjective Theory 'loss of biodiversity due to ecological reasons'. The larger the squares are, the greater the number of arguments pertaining to the respective category of ecological, economical, or social arguments. Steps of the interview: 1) General questions and input example Devil's Claw, 2) Boldo transfer example and 3) possible solutions suggested by the pupils. Ecological arguments are highlighted by the rectangles 
correspond with a stronger ecological knowledge base in pupils. A fourth characteristic of those pupils in whom we identified the subjective theory 'loss of biodiversity due to ecological reasons' was that they often expressed negative judgements toward plant collectors in a resource dilemma. We therefore assume that a focus on ecological aspects of resource dilemmas might generally correlate with a lack in empathy for people who depend on natural resources. This lack of empathy is alarming, for two reasons. Firstly, blank negative judgements of people in difficult economic situations are unfair attributions of responsibility. Secondly, research has shown that an ability to show empathy can have a positive influence on pro-environmental attitudes and behaviours (Berenguer 2007), a potential that can not be tapped for these pupils.

Although qualitative data from small samples does not allow for broad generalisations, the study shows a general prevalence of the subjective theory 'loss of biodiversity due to ecological reasons' across the Chilean and the German sample (see Fig. 2). A similar finding has also been reported as a result of an earlier study with only German pupils (Menzel and Bögeholz 2006).

In particular, Natascha's profile and the profile of the other pupils clearly demonstrate that the subjective theory 'loss of biodiversity due to ecological reasons' had at least two main negative consequences for the learning process:

1. The potential application of weak ecological facts whenever 'accurate' ecological arguments fail to explain biodiversity loss;

2. The absence of empathy with people in real resource dilemmas due to difficulties in recognizing social-economic traps as a cause for biodiversity loss.

\section{Subjective Theory 2: Loss of Biodiversity Due to Economic Reasons}

A second subjective theory 'loss of biodiversity due to economic reasons' emerged from the data. Here, pupils characterized market forces as the driving force in the protection or depletion of a resource. This subjective theory will be exemplified by the profile of the Chilean pupil Elena who mentioned the following thoughts: '[I think the people's interest in collecting the plant] is money [...]. Some pharmaceutical enterprises might preserve [the plants], [in order] to be able to sell products. However, they [still] go on producing, possibly without any conscience [...]. [This might happen] to satisfy their needs, but in the end, it's all for the money' (294-296, 300-301). With respect to Elena's position, the situation pertaining to Boldo was similarly sketched: '[I would judge the behaviour of the persons participating in the process] ambitious or maybe that they only care for mass production and selling, and not [for the fact that] they do harm to nature or to the ecosystem where they take the things from' (426-428). What is of particular interest in the case of Elena, are the solutions that she developed during the third phase of the interview. Elena assumed that the Alerce, an endemic Chilean tree, would only be protected once the tree's economic value is recognized. Accordingly, Elena considered possible disadvantages for such species that do not show an economic value, provided by the following datum: [...] for example, if they [the companies] use resources such as the Alerce, [they] will be more protected, because in the end [...] money always makes a difference. So if they use half of [the money available for conservation purposes] for Alerces, there will be less protection, less care for other species to which they assign less money' (547-550). Here, monetary value was considered as a factor that plays the decisive role in protecting a plant. On the one hand, this thought suggests the possibility of conservation through sustainable use, which is one of the main conservation strategies expressed in the Convention on 
Biological Diversity. On the other hand, her assumption that plants of economic value would automatically be protected did not correlate favourably with the examples presented to the interviewees and was, therefore, somewhat naïve.

Elena also described greed for money as a reason for the depletion of a resource. Thus, overall, she seemed to be ambivalent about the role that money plays. Interestingly, although economic considerations formed the basis for her arguments, they remained at the more abstract level of market forces. In doing so, Elena neither considered the plant collector's economic situation nor the consumer's role as potential purchaser of a product, nor for the possibility of sustainable economies, such as the 'fair trade' idea.

The subjective theory 'loss of biodiversity due to economic reasons' could only be identified with the Chilean pupil Elena. However, two other pupils, Andreas (German) and Maria (Chilean), showed economic forces similar to those of Elena. Here, cognitive frameworks could be identified on the level of concepts (as their arguments appeared more isolated from each other and were, thus, not stable enough to be considered a subjective theory). An overview of the argumentative structure across the three interview stages is presented in Fig. 3 below.

Elena, Andreas and Maria showed some parallels in their arguments that go beyond the focus on economic forces. For example, all three pupils considered consequences for commercial trade following an elimination of the plant, but not the elimination of the plant as a result of excessive trade. A similar approach was found in the context of Boldo, which was also frequently discussed as an economic consumable. However, even though a large emphasis was placed on an economical aspect, the two Chilean pupils also reflected upon ecological consequences of the loss of Boldo. In particular, they considered a disturbance of the ecosystem caused by the loss of the plant. Nevertheless, social consequences were not reflected. If we regard judgements of the plant collector's role, negative evaluations occurred, especially in the case of Maria (Chilean), who on seven occasions blamed plant collectors for threatening Boldo. Andreas (German) blamed plant collectors once, and Elena (Chilean) did so as well, on four occasions. It thus seems as if the subjective theory 'loss of biodiversity due to economic reasons' does not favour a consideration of socio-economic aspects of resource dilemmas. In particular, Elena's profile and the profiles of Maria and Andreas showed that:

1. A consideration of economic forces does not automatically correspond with the recognition of sustainable economies as a solution;

Fig. 3 Loss of biodiversity due to economic reasons. Predominant arguments are economic within the first part of the interview and are also transferred onto the Boldo example (step 2 of the interview). Economic arguments are highlighted by the rectangles

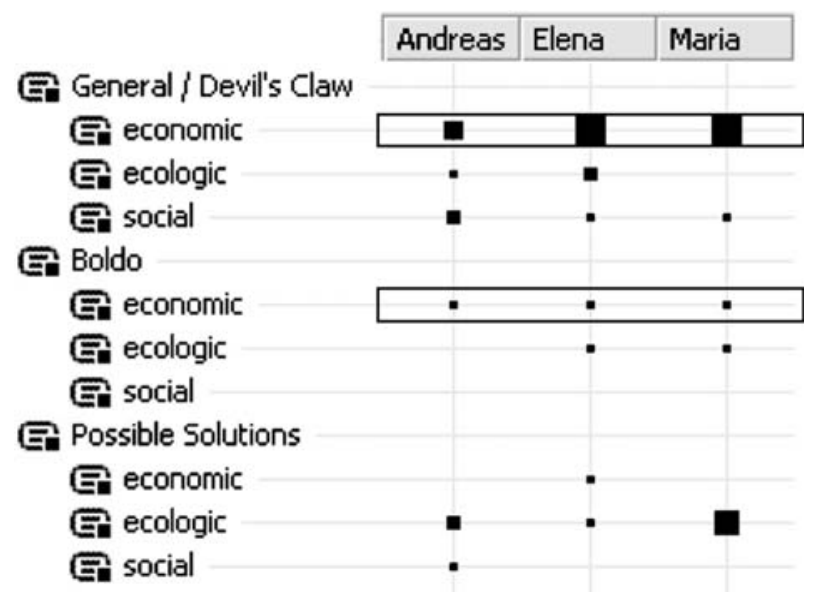


2. Economic forces were considered at a rather abstract level without reflecting upon the role of individuals (such as those in resource dilemmas or consumers).

\section{Subjective Theory 3: Loss of Biodiversity Due to Social Reasons}

A third subjective theory was 'loss of biodiversity due to social reasons', which is characterized by mentioning social aspects of resource dilemmas throughout the entire interview. In this subjective theory, economic and ecological aspects played a certain role but were usually likewise considered under a social perspective. To demonstrate the nature of this theory, the profile of Katja (German) will be examined. Katja described the example of Devil's Claw as follows: 'I think [the situation is so complicated because] the people harvesting it [the plant], somehow need that money, otherwise they wouldn't have a means of subsistence. And maybe they don't have the chance to do something else and that they really need the money [makes the situation so difficult]' (398-401). When talking about Boldo, Katja again focused her arguments on the plant harvester's socio-economic situation, in this case on the need for income as demonstrated by the following: 'I would suggest that [concerning the main participants of the trade with Boldo] again, there are plant collectors receiving a salary for it [the plant] which is then exported to us' (463-465). According to the underlying subjective theory, Katja's solutions were also aimed at addressing the social and economic situation, which is supported by the following: 'One has to offer other possibilities to the people to be able to earn money' $(412,416)$. Later during the same interview, Katja considered a prevention of trade of Boldo as a possible solution, but then strongly emphasized social aspects again as shown below: '[...] it would be over for them [the collectors] as well. If there is no demand, they wouldn't earn any money' (489-490). The subjective theory 'loss of biodiversity due to social reasons' was a strong underlying, structuring element in the case of Katja. However, Katja did not exclusively draw upon social aspects of resource dilemmas. Rather, Katja's underlying subjective theory fostered the likewise inclusion of ecological, economic and social perspectives. For example, she placed a strong emphasis on a need for money as an indirect threat to biodiversity, but she also reflected the role of traders, exporters, and consumers within the same argument. It was Katja's careful thought about the lack of income alternatives that might have prevented her from suggesting solutions that could probably worsen the plant collector's situation. Katja showed empathy and never blamed the plant collectors directly for depleting the resource. Katja's statements highlight the high potential of the 'biodiversity' subject as means for fostering links between science, society and environmental education (e.g. Van Weelie 2002). Apparently, Katja was able to comprehend both, the ethical and factual complexity (Barkmann and Bögeholz 2003) of the biodiversity concept. Besides Katja, six other pupils continuously drew upon social aspects during the interview (cf. Fig. 4).

Just like Katja, these pupils took the plant collector's weak economic situation and their social dependence on natural resources into consideration. As a consequence, pupils also considered conflicts in interest between sustainable exploitation of a resource on the one hand, and a satisfaction of basic economic needs on the other. Interestingly, negative evaluations of the plant collector's role occurred less frequently in combination with the subjective theory 'loss of biodiversity due to social reasons'. Only Julia (German), and Carlos (Chilean) described the plant collector's role in a negative way. Overall Julia criticised the exploitation of the plant by collectors only once, yet Carlos did so on five occasions. Moreover, Carlos was the only pupil of this group who did not mention thoughts about social solutions. 
Although quantitative methods with a larger sample would be necessary for constructing correlations between arguments, the qualitative data nevertheless suggest a strong relationship between the subjective theory 'loss of biodiversity due to social reasons' and the participant's ability to show empathy. In summary, Katja's profile and the profiles of the other pupils with the subjective theory 'loss of biodiversity due to social reasons' show that:

1. A consideration of the plant collector's perspective took place during the discussion of resource dilemmas, and empathy with people in resource dilemmas was imparted;

2. Most of the pupils who showed the subjective theory 'loss of biodiversity due to social reasons' used ecological, economic, and social arguments in all three stages of the interview rather than focusing on one sphere only.

\section{Chilean and German Subsample}

Regarding the subjective theories identified in this study, two notable phenomena distinguish the two samples:

i. The subjective theory 'loss of biodiversity due to social reasons' could mainly be identified in German pupils. The only Chilean pupil who displayed this subjective theory, Carlos, did not suggest social solutions.

ii. The second dilemma example, incorporating the Latin American medical plant Boldo, was not identified as a resource dilemma by a group of five Chilean pupils (cf. Fig. 2).

Reasons contributing to the above mentioned phenomena can be diverse. One reason might be a stronger disciplinary orientation of school curricula in Latin America, which still focus less on interdisciplinary thinking in environmental education (González-Gaudiano 2007). In particular, the result contradicts our initial expectation that Chilean pupils would be more open to social explanations for biodiversity loss (i.e. showing empathy with people caught in resource dilemmas) due to the proximity of the biodiversity hotspot. Ostuni (2006) has reported findings similar to those of our study and concluded that the interrelations of environment, society and economy have to be emphasized more in South American countries, in order to encourage empathy and solidarity.

One explanation for the difficulties of Chilean pupils to recognize the local example Boldo could be the large presence of Boldo leafs on local markets. Such an observation might lead to the interpretation of the resource to be abundant. In this regard, the example of Boldo shows that Chilean pupils constructed their knowledge directly from individual everyday-life experiences. In this case, the subjective construction of knowledge resulted in

Fig. 4 Loss of biodiversity due to social reasons. Social arguments appear within all three steps of the interview. Social arguments are highlighted by the rectangles

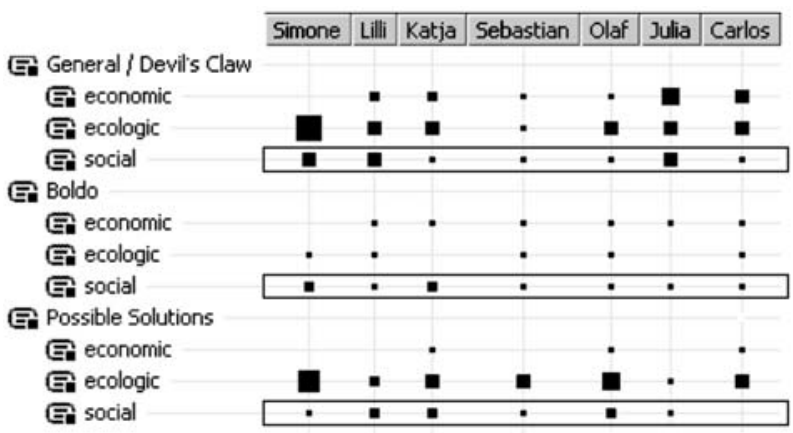


an overestimation of the resource's natural abundance and, therefore, to an incorrect conclusion.

\section{Educational Implications}

The results provide an empirical basis for some suggestions with regard to content and pedagogy of biodiversity education. Initially, the term for 'biodiversity' should be introduced into German science classes, probably by presenting it as the technical term for 'biological diversity' (which was commonly more familiar to German pupils). Furthermore, educators have to emphasize the various facets of biodiversity, since the data showed that it was often interpreted as a synonym for 'variety of species', rather than a consideration of all three types of biodiversity. Pupils though did seem to be open towards the biodiversity of ecosystems, which is a good starting point. Moreover, the notion of genetic diversity as the engine of evolution and 'insurance' for survival under changing environmental conditions, could serve as a valuable introduction to achieve a basic understanding of genetic variety. Furthermore, an adequate and complete introduction of the terms 'biodiversity' and 'biological diversity' should also help to overcome the popular misinterpretation of the term 'biodiversity' as some or other sub discipline of biology-an interpretation that occurred within both samples.

The results with regard to the concept 'lack of space' suggest that the concept should be broadened to enhance the understanding of habitat destruction outside big cities. Besides this, examples of synanthropes (i.e. species that benefit from environmental modifications made by humans, such as the feral pigeon or the house sparrow, cf. Allaby 1998) could highlight the fact that biodiversity is not absent from big cities. By pointing out the fact that cities sometimes serve as species' habitat, a context involving cognitive conflict could be used, which challenges the concept of 'lack of space'.

The concept of 'low biodiversity due to extreme climatic circumstances' may also hinder the learning process. To avoid this, the concept of climatic extremes should be made explicit by including examples of highly adapted plant and animal species in biodiversity education. This is also important, in order to prepare pupils for the public discourse on climate change. It is particularly important to understand that during evolution, climatic extremes per se lead to highly diversified biocenoses (i.e. life assemblages of plants, animals, and microorganisms), while rapid changes might, indeed, threaten species and ecosystems (e.g. Pounds et al. 1999).

With regard to local biodiversity, educational measures in Germany should enhance sensitivity towards the numerous species that are threatened on a local scale. In doing so, educational measures could also serve as motivational factors towards protecting biodiversity (Lindemann-Matthies 2006). Although mentioning numerous examples for threatened species, Chilean pupils tended to have difficulties in understanding the local resource dilemma, probably due to the vast presence of the respective resource within the scope of the pupil's everyday life experience. This finding strongly suggests that educators must not assume an easier understanding for resource dilemmas and biodiversity loss just because it happens on the learner's doorstep. Rather, a deeper understanding of the strongly interwoven socio-economic and ecological facts needs to be stressed. This can only be achieved if room is given to real-world examples - and if enough time is provided to disentangle and understand the complex interrelations causing biodiversity loss.

Regarding the value of biodiversity, pupils easily recognized the actual usefulness of biodiversity for human benefit. This could be a good starting point for devising learning 
interventions, for example, which require critical reflection. Educational measures should also stress that the protection of biodiversity must not be motivated exclusively for human benefit. An approach in the discussion of the values of biodiversity should also include non-monetary benefits such as aesthetic value, as these were seldom mentioned, especially within the Chilean sample.

Obviously the largest challenge for biodiversity education is the inclusion of socioeconomic aspects. According to our data, such an inclusion is important for two reasons: Firstly, in order to be able to show empathy and solidarity with people in resource dilemmas; secondly, to apply ecological knowledge more appropriately by not making up facts whenever an ecological focus has shortfalls in explaining the situation. However, many science teachers are still uncomfortable about the inclusion of socio-scientific issues in their classes (Gayford 2000; Summers et al. 2005). The data of the present study, therefore, supports the claim that teacher education needs to address this issue to overcome the teacher's reservations in this respect (Gayford 2000; Summers et al. 2005). To foster empathy in teaching practice, role-play in which pupils are encouraged to take a different perspective could be a useful approach. Furthermore, in teamwork tasks, pupils who are able to show such empathy could support those classmates who are having difficulty taking the perspective of people in resource dilemmas. Moreover, besides the social drivers for biodiversity loss, an economic perspective is important with respect to a complete understanding of resource dilemmas. The Convention on Biological Diversity (UNCED 1992) explicitly suggests the protection of biodiversity through sustainable utilisation. In this regard, some pupils mentioned interesting thoughts, especially those who showed the subjective theory 'loss of biodiversity due to economic reasons' (or, at least, corresponding concepts). In teaching practice, thoughts about the economic value of natural resources could be gradually extended to new domains, such as sustainable business that also addresses the difficult economic situation of plant collectors rather than focusing on economic profit alone. Sadler et al. (2007) described how exemplary scenarios can be used to enhance the pupil's socio-scientific reasoning, i.e. towards a better description and understanding of conflicting interests of competing stakeholders. Especially in the Chilean context, such real-world approaches could be helpful to broaden the pupil's perspective on resource dilemmas. Pupils who showed the subjective theory 'loss of biodiversity due to social reasons' better understood the complex and interdisciplinary aspects that lead to the loss of biodiversity. Such thinking should be supported-and encouraged in those pupils who have not yet achieved such multidimensional thinking. Teaching material such as the World Wildlife Fund 'Linking Thinking' toolbox (Sterling 2004), explicitly supports such multidimensional thinking, and is a precious source to overcome the deficits in multidimensional thinking as shown by the results of the herewith presented research.

\section{Future Perspectives}

A further research question is: why some pupils are able to consider an interdisciplinary perspective, while others are not? In this respect, social psychological theories, such as the Value-Belief-Norm Theory (e.g. Stern 2000), provide interesting approaches that can be used to explain an individual's commitment to protect the environment. Hence, a further quantitative study that applies the theory to the context of biodiversity with further samples of German and Chilean adolescents could clarify differences amongst perceptions. Furthermore, identifying predictors for a commitment to protect biodiversity, would contribute to the knowledge-base of biodiversity education. Together with the herewithreported research, biodiversity education could then build upon a stronger empirical basis. 
Acknowledgements We would like to thank the two anonymous reviewers for their extraordinarily helpful comments!

Open Access This article is distributed under the terms of the Creative Commons Attribution Noncommercial License which permits any noncommercial use, distribution, and reproduction in any medium, provided the original author(s) and source are credited.

\section{References}

Allaby, M. (ed.) (1998). Dictionary of ecology. Oxford: Oxford University Press.

Balmford, A., Clegg, G., Coulsen, T., \& Taylor, J. (2002). Why conservationists heed Pokémon. Science, 295, 2367. doi:10.1126/science.295.5564.2367b.

Barkmann, J., \& Bögeholz, S. (2003). Kompetent gestalten, wenn es komplexer wird-Eine kurze Einführung in die ökologische Bewertungs - und Urteilskompetenz [A short introduction to ecological decision making competence]. Zeitschrift 21, 49-52.

Bebbington, A. (2005). The ability of A-level students to name plants. Journal of Biological Education, 39, 62-67.

Berenguer, J. (2007). The effect of empathy in proenvironmental attitudes and behaviors. Environment and Behaviour, 39, 269-283. doi:10.1177/0013916506292937.

Caravita, S., \& Halldén, O. (1994). Re-framing the problem of conceptual change. Learning and Instruction, 4, 89-111. doi:10.1016/0959-4752(94)90020-5.

Carey, S. (1985). Conceptual change in childhood. Cambridge: MIT.

Cincotta, R. P., Wisnewski, J., \& Engelman, R. (2000). Human population in the biodiversity hotspots. Nature, 404, 990-992. doi:10.1038/35010105.

Dreyfus, A., Wals, A. E. J., \& Van Weelie, D. (1999). Biodiversity as a postmodern theme for environmental education. Canadian Journal of Environmental Education, 4, 155-175.

Duit, R., \& Treagust, D. (2003). Conceptual change: a powerful framework for improving science teaching and learning. International Journal of Science Education, 25, 671-88. doi:10.1080/09500690305016.

Ernst, A. (1997). Ökologisch-soziale Dilemmata [Resource dilemmas]. Weinheim: Psychologie Verlags Union.

Gayford, C. (2000). Biodiversity education: a teacher's perspective. Environmental Education Research, 6 , 347-361. doi:10.1080/713664696.

González-Gaudiano, E. (2007). Schooling and environment in Latin America in the third millennium. Environmental Education Research, 13, 155-169. doi:10.1080/13504620701295684.

Grace, M., \& Ratcliffe, M. (2002). The science and values that young people draw upon to make decisions about biological conservation issues. International Journal of Science Education, 24, 1157-69. doi:10.1080/09500690210134848.

Groeben, N., Wahl, D., Schlee, J., \& Scheele, B. (1988). Das Forschungsprogramm Subjektive Theorien [The research programme subjective theories]. Tübingen: Francke.

Gropengießr, H. (2001). Didaktische Rekonstruktion des Sehens [Didactical reconstruction with 'seeing' as an example]. Oldenburg: Didaktisches Zentrum.

Hardin, G. (1968). The tragedy of the commons. Science, 162, 1243-1248. doi:10.1126/science.162.3859.1243.

Huckle, J., \& Sterling, S. (Eds.). (1996). Education for sustainability. London: Earthscan.

International Union for Conservation of Nature (IUCN) (2007). Red list of endangered species. Gland: The World Conservation Union.

Kassas, M. (2002). Environmental education: biodiversity. The Environmentalist, 22, 345-351. doi:10.1023/ A:1020766914456.

Lindemann-Matthies, P. (2006). Investigating nature on the way to school: responses to an educational programme by teachers and their pupils. International Journal of Science Education, 8, 895-910. doi:10.1080/10670560500438396.

Mallow, D. (1994). Biodiversity. The Science Teacher, 61, 19-21.

Marshall, N. T. (1998). Searching for a cure-conservation of medical wildlife resources in East and Southern Africa (TRAFFIC Network Report). Cambridge: TRAFFIC.

Menzel, S., \& Bögeholz, S. (2006). Vorstellungen und Argumentationsstrukturen von Schüler(inne)n der elften Jahrgangstufe zur Biodiversität, deren Gefährdung und Erhaltung [Cognitive frameworks and argumentation structures of 11th-grade-pupils about biodiversity, threats for it and its conservation]. Zeitschrift für die Didaktik der Naturwissenschaften, 12, 199-215.

Miles, M. B., \& Huberman, M. A. (1994). Qualitative data analysis. Thousand Oaks: Sage.

Mittermeier, R. A., Robles Gil, P., Hoffmann, M., Pilgrim, J., Brooks, T., Mittermeier, C. G., et al. (2004). Hotspots revisited. Mexico: CEMEX. 
Ostuni, J. (2006). South America and education for sustainable development. Australian Journal of Environmental Education, 22, 87-90.

Piaget, J. (1974). Der Aufbau der Wirklichkeit beim Kinde [The construction of reality in the child]. Stuttgart: Klett.

Posner, G. J., Strike, K. A., Hewson, P. W., \& Gertzog, W. A. (1982). Accommodation of a scientific conception: toward a theory of conceptual change. Science Education, 66, 211-227. doi:10.1002/ sce. 3730660207 .

Pounds, A. J., Fogden, M. P. L., \& Campbell, J. H. (1999). Biological response to climate change on a tropical mountain. Nature, 398, 611-615. doi:10.1038/19297.

Pullin, A. S. (2002). Conservation biology. Cambridge: Cambridge University Press.

Sadler, T., Barab, S. A., \& Scott, B. (2007). What do students gain by engaging in socioscientific inquiry. Research in Science Education, 37, 371-391. doi:10.1007/s11165-006-9030-9.

Scholz, I. (1999). Medio ambiente y competitividad: el caso de exportaciones chilenas [Natural environment and competition: the case of Chilean exports]. In K. Eßer (Ed.), Competencia global y libertad de acción nacional (pp. 99-116). Caracas: Libros.

Scott, W., \& Gough, S. (Eds.). (2003). Sustainable development and learning. Framing the issues. London, New York: Routledge Falmer.

Sterling, S. (2001). Sustainable education. re-visioning learning and change. Foxhole, Dartington, Totnes, Devon: Green Books.

Sterling, S. (2004). Linking thinking. Perthshire: WWF Scotland.

Stern, P. C. $(2000)$. Toward a coherent theory of environmentally significant behavior. Journal of Social Issues, 56, 407-424. doi:10.1111/0022-4537.00175.

Strube, G. (1984). Assoziation: der Prozess des Erinnerns und die Struktur des Gedächtnisses [Associations: the process of remembrance and the structure of mind]. Berlin: Springer.

Summers, M., Childs, A., \& Corney, G. (2005). Education for sustainable development in initial teacher training: issues for interdisciplinary collaboration. Environmental Education Research, 11, 623-647. doi:10.1080/13504620500169841.

Townsend, C. R., Begon, M. E., \& Harper, J. L. (2003). Essentials of ecology. Oxford: Blackwell.

UNCED, United Nations Conference on Environment and Development (1992). Convention on biological diversity $(C B D)$. Rio de Janeiro: UNCED.

Van Weelie, D. (2002). Making biodiversity meaningful by environmental education. International Journal of Science Education, 24, 1143-1156. doi:10.1080/09500690210134839.

Vogel, H., Doll, U., Muñoz, M., Razmilic, I., San Martin, J., \& Vizcarra, G. (1998). Boldo (Peumus boldus Mol.) - Vermehrungsversuche und ökophysiologische Studien am natürlichen Standort in Chile [Boldofertility experiments and ecophysiological studies in the natural habitat Chile]. Drogenreport, 11, 14-17.

von Glasersfeld, E. (2005). Radikaler Konstruktivismus: Ideen, Ergebnisse, Probleme [Radical constructivism. Ideas, results, challenges]. Frankfurt am Main: Suhrkamp.

Vosniadou, S. (1992). Knowledge acquisition and conceptual change. Applied Psychology, 41, 347-357. doi:10.1111/j.1464-0597.1992.tb00711.x.

Wilson, E. O. (2001). The diversity of life (2nd ed.). London: Penguin.

WCED, World Commission on Environment and Development (1987). Our common future. Oxford: Oxford University Press. 